\title{
Landspreading as a waste disposal option for contaminated milk
}

\author{
J. Marchant and A. Nisbet \\ National Radiological Protection Board, Environmental Assessments Department, \\ Chilton OX11 ORQ, U.K.
}

\begin{abstract}
In the event of a nuclear accident, there may be significant quantities of agricultural produce contaminated with radionuclides that require disposal. The disposal of milk would be of particular concern, since the quantities classed as waste could be substantial and extensive environmental damage could be caused if this was not disposed of appropriately. As part of contingency planning for potential nuclear accidents, the identification of practicable options for disposal of contaminated milk is therefore important. One of the potential options is disposal by landspreading. The practicability of landspreading has been evaluated against a set of six important criteria: technical feasibility, existing capacity, cost, environmental impach radiological impact and acceptability. Information was obtained through wide consultation. The radionuclides of interest were ${ }^{131} \mathrm{I}$, ${ }^{134,137} \mathrm{Cs}$ and ${ }^{89,90} \mathrm{Sr}$. Landspreading is a technically feasible and relatively inexpensive disposal option for milk that appears acceptable in principle to both farmers and regulators. The radiological impact of landspreading is low. However, the environmental impact due to the high BOD and nitrogen content of milk may limit the amounts that can be spread in sensitive areas. Limited storage capacity and availability of suitable land are additional factors that can further limit capacity at certain times of the year.
\end{abstract}

\section{INTRODUCTION}

In the event of a nuclear accident, there may be significant quantities of agricultural produce that are contaminated with radionuclides and require disposal. In the UK, restrictions would be imposed on the supply of foodstuffs with activity concentrations in excess of the Council Food Intervention Levels (CFIL) for human consumption specified by the European Community (Table 1). The disposal of milk would be of particular concem, since the quantities involved could be substantial and extensive environmental damage could be caused if the material was not disposed of properly. As part of contingency planning for future nuclear accidents, the identification of practicable options for the disposal of contaminated milk is therefore important. In the UK, the Food Standards Agency, the Environment Agency and the National Radiological Protection Board have jointly funded a project to evaluate a number of options for the management of waste milk, including the potential for disposal by landspreading.

Table 1: CFILS for dairy produce [1]

\begin{tabular}{|lr|}
\hline Radionuclide & $\begin{array}{l}\text { CFIL, } \\
\mathrm{Bq} \mathrm{kg}^{-1} \text { fresh }\end{array}$ \\
\hline${ }^{134,137} \mathrm{Cs}$ & 1,000 \\
${ }^{89,90} \mathrm{Sr}$ & 125 \\
${ }^{131}{ }^{1} \mathrm{I}$ & 500 \\
\hline
\end{tabular}


An evaluation of the practicability of landspreading milk contaminated as a result of a nuclear accident has been carried out and a detailed account has been published [2]. This paper provides a summary of the results. The objectives of this work were as follows:

- To establish the current extent and legal position of landspreading contaminated milk on farmland in England and Wales.

- To assess the practicability of landspreading contaminated milk according to the following criteria: technical feasibility, capacity, cost, environmental impact, radiological impact and acceptability.

- To evaluate landspreading as a waste disposal option under realistic deposition scenarios.

\section{LEGISLATION}

The legislation and guidance for farmers is dominated by the Codes for Good Agricultural Practice, which are issued by the Ministry for Agriculture Fisheries and Food (MAFF) [3,4]. These are practical guides to help farmers avoid causing water and air pollution from the landspreading of animal wastes, including milk. However, if milk is considered to be high-risk material because it contains radionuclides in excess of the CFL, the Animal By-Products Order (1999) would seek to prohibit it from being spread on land. Therefore, the legal situation with regard to the landspreading of radionuclide contaminated milk. still needs clarification.

\section{EVALUATION OF PRACTICABILITY}

The practicability of landspreading as a disposal option in the UK was evaluated according to six important criteria as outlined below. Information on all of these factors except radiological impact was obtained from the literature and through consultation with representatives from a large number of organisations including regulatory bodies, research organisations and private companies. In addition, a small postal survey of individual farmers was carried out to establish current practices.

\subsection{Technical feasibility}

Disposal of milk by landspreading is an existing practice that is currently undertaken on occasions if quota is exceeded, bad weather has prevented collection, or the milk has become contaminated. Milk is usually spread in combination with slurry and is stored in the slurry tank prior to spreading. Landspreading of milk is clearly technically feasible, as both the techniques and equipment required to undertake it are readily available.

\subsection{Capacity}

The capacity for landspreading milk could be restricted by the storage facilities on the farm and the availability of suitable land. These vary considerably between farms and are very dependent on the time of the year that the accident occurs. The times at which slurry would need to be disposed of would not coincide with the times at which waste milk is most likely to be produced. Slurry is generated while the cattle are housed between November and March. In contrast waste milk would most probably be produced whilst the cattle were consuming contaminated pasture between April and October. The most critical time with regard to capacity would be when slurry tanks were almost full and landspreading was not possible due to a risk of pollution.

\subsection{Costs}

Landspreading of waste milk has minimal costs associated with it. The major cost is likely to involve compensating farmers for the milk that they are unable to sell. If it is assumed that the milk is landspread along with the slurry, then the extra work for the farmer would be minimal, involving only dealing with 
larger quantities than normal. A certain amount of compensation would be necessary for this extra work. Also, in situations where equipment is contaminated, costs for decontamination would be incurred.

\subsection{Environmental Impact}

Milk has a very high biochemical oxygen demand (BOD) and high nitrogen content and so may cause pollution if allowed to enter a watercourse. Consequently, the landspreading of milk, particularly in large quantities, should be carried out in accordance with current guidelines. To minimise environmental impact, milk should be applied to arable land from February to May when the nutrients that are released during decomposition can be taken up by growing plants. On grassland, applications should be made whenever the grass is actively growing (i.e. not restricted by drought or cold), which is also likely to be in the spring. Any large-scale applications should be monitored closely.

\subsection{Radiological Impact \\ 3.5.1 Estimated doses to farmers and members of the public}

Doses were estimated to both farmers and members of the public from landspreading milk contaminated with ${ }^{131} \mathrm{I},{ }^{134,137} \mathrm{Cs}$ and ${ }^{89,90} \mathrm{Sr}$, assuming that restrictions were in place for periods of either 1,2 or 3 months. For each of the radionuclides considered, it was assumed that the activity concentrations in milk at the end of these periods were equal to the relevant CFIL (Table 1). The NRPB dynamic foodchain model FARMLAND [5] was used to estimate the corresponding activity concentrations in milk at earlier times during the period of restriction so that the average activity concentration in the waste milk could be estimated. When estimating doses, no account was taken of exposure to activity already present in the environment as a result of deposition: the estimated values represent only the incremental doses received as a result of implementing the option.

For farmers, the operations considered were loading, spreading and ploughing. During these operations, the relevant exposure pathways for farmers would be external irradiation, inhalation of resuspended material and inadvertent ingestion. The estimated doses to farmers from spreading contaminated milk on dairy farms are given in Table 2 . The corresponding doses on mixed farms would be lower, because there would be fewer dairy cows and therefore correspondingly smaller volumes of contaminated milk to be handled.

Table 2: Estimated doses to farmers on dairy farms ${ }^{(a)}$ from spreading contaminated milk ${ }^{(b)}$ assuming that the activity concentrations are at the CFIL when restrictions are lifted after 1,2 and 3 months ${ }^{\text {(c) }}$

Notes

\begin{tabular}{|l|l|l|l|l|l|}
\hline \multirow{2}{*}{$\begin{array}{l}\text { Period of } \\
\text { restriction, months }\end{array}$} & \multicolumn{5}{|c|}{ Individual dose $\left(\mu \mathrm{Sv} \mathrm{y}^{-1}\right)$} \\
\hline 1 & ${ }^{89} \mathrm{Sr}$ & ${ }^{90} \mathrm{Sr}$ & ${ }^{134} \mathrm{Cs}$ & ${ }^{137} \mathrm{Cs}$ & ${ }^{131} \mathrm{I}$ \\
\hline 2 & $1.22 \mathrm{E}-06$ & $3.08 \mathrm{E}-05$ & $5.30 \mathrm{E}-02$ & $2.18 \mathrm{E}-02$ & $2.42 \mathrm{E}-05$ \\
\hline 3 & $5.65 \mathrm{E}-06$ & $9.93 \mathrm{E}-05$ & $2.48 \mathrm{E}-01$ & $9.97 \mathrm{E}-02$ & $2.43 \mathrm{E}-03$ \\
\hline
\end{tabular}

(a) The milk yields for an average dairy farm were calculated using data from Chadwick [6]. The annual milk yield per cow was taken as 6000 litres and the average dairy farm in England has 82 dairy cows.

(b) It was assumed that all milk produced on the farm over the time periods considered is landspread. The milk was assumed to be diluted by slurry and waste waters. The dilution was set at 0.13 assuming the store is empty at the time of the accident and that the milk, slurry and waste waters were added at the rate at which they are produced. The rate of application was set at $20 \mathrm{tha}^{-1}$

(c) It was assumed that after restrictions had been lifted, the waste milk was stored for 3 months before spreading

Doses to adult members of the public were calculated from ingestion of green vegetables, root vegetables, potatoes, meat, liver and milk from cows and meat and liver from sheep produced on mixed farms where landspreading has been carried out. Doses to members of the public from cereal were not considered because it was assumed that cereal in the diet derives mainly from national rather than local production. A cautious approach was taken, whereby it was assumed that all the relevant foodstuffs in the diet came from a contaminated area and that the two foods giving the highest doses wcrc consumed at 
higher than average rates whilst the remaining foods were consumed at average rates. This approach is based on work carried out by MAFF [7]. The estimated doses to adult members of the public from mixed farms are shown in Table 3. The corresponding doses for dairy farms would be lower, because fewer food categories would be contaminated.

At the spreading rates used in this assessment, the highest doses were to members of the public from ingestion of food contaminated with radiocaesium. All doses to both farmers and members of the public were found to be below the $10 \mu \mathrm{Svy}^{-1}$ dose considered trivial for regulatory purposes [8]. It should be noted that doses to the public are highly influenced by the rate at which the milk is spread on the land. The assessment made use of a rate equivalent to that currently used by farmers when spreading milk/slurry on the land. If more land was available however, it could be possible to spread at a lower rate and thereby reduce these doses.

Table 3: Estimated doses from ingestion to members of the public from spreading milk contaminated at the average activity concentration over 1,2 and 3 month ban durations on a mixed farm

\begin{tabular}{|l|l|l|l|l|l|}
\hline $\begin{array}{l}\text { Period of } \\
\text { restriction, months }\end{array}$ & \multicolumn{5}{|c|}{ Individual dose $\left(\mu \mathrm{Sv} \mathrm{y}^{-1}\right)$} \\
\hline 1 & ${ }^{89} \mathrm{Sr}$ & ${ }^{90} \mathrm{Sr}$ & ${ }^{134} \mathrm{Cs}$ & ${ }^{137} \mathrm{Cs}$ & ${ }^{33} \mathrm{I}$ \\
\hline 2 & $5.49 \mathrm{E}-04$ & $1.53 \mathrm{E}-01$ & $4.59 \mathrm{E}-01$ & $3.46 \mathrm{E}-01$ & $2.07 \mathrm{E}-05$ \\
\hline 3 & $1.30 \mathrm{E}-03$ & $2.55 \mathrm{E}-01$ & 1.11 & $8.15 \mathrm{E}-01$ & $1.04 \mathrm{E}-03$ \\
\hline
\end{tabular}

\subsubsection{Limiting concentrations}

Table 4 gives the activity concentration of each radionuclide in milk that would give rise to an incremental dose of $10 \mu \mathrm{Sv} \mathrm{y}^{-1}$ to a farmer or a member of the public from landspreading, when the land is subsequently used for food production. The limiting concentrations were in all cases due to the dose to the public from consumption of food produced on the treated land. Consequently, the limiting concentrations were independent of the period of restriction. This is because it is assumed that each area of land is only landspread once. Therefore, if greater quantities of milk require disposal, then doses to an individual member of the public would be the same, but more people would be affected. The concentrations that can be spread on dairy farms are very similar to those that can be spread on mixed farms. The limiting concentrations are in all cases greater than the corresponding CFIL, by more than a factor of 10 and greatly exceed the concentrations envisaged for potential nuclear accidents in the UK.

Table 4: Limiting concentrations of radionuclides in milk that can be landspread on both dairy and mixed farms when land used for food production

\begin{tabular}{|l|l|l|l|l|l|l|}
\hline Period of restriction, & \multirow{2}{*}{ Farm Type } & \multicolumn{2}{|l|}{ Limiting Concentrations Bq kg-1 } \\
\cline { 3 - 7 } months & & $1.08 \mathrm{E}+06$ & $5.09 \mathrm{E}+04$ & $1.72 \mathrm{E}+05$ & $2.07 \mathrm{E}+05$ & $1.34 \mathrm{E}+09$ \\
\hline 1 & Dairy & $1.08 \mathrm{E}+06$ & $5.09 \mathrm{E}+04$ & $1.72 \mathrm{E}+05$ & $2.07 \mathrm{E}+05$ & $1.34 \mathrm{E}+09$ \\
\hline 2 & Dairy & $1.08 \mathrm{E}+06$ & $5.09 \mathrm{E}+04$ & $1.72 \mathrm{E}+05$ & $2.07 \mathrm{E}+05$ & $1.34 \mathrm{E}+09$ \\
\hline 3 & Dairy & $6.93 \mathrm{E}+05$ & $6.28 \mathrm{E}+03$ & $6.26 \mathrm{E}+04$ & $8.19 \mathrm{E}+04$ & $6.59 \mathrm{E}+08$ \\
\hline 1 & Mixed & $6.93 \mathrm{E}+05$ & $6.28 \mathrm{E}+03$ & $6.26 \mathrm{E}+04$ & $8.19 \mathrm{E}+04$ & $6.59 \mathrm{E}+08$ \\
\hline 2 & Mixed & $6.93 \mathrm{E}+05$ & $6.28 \mathrm{E}+03$ & $6.26 \mathrm{E}+04$ & $8.19 \mathrm{E}+04$ & $6.59 \mathrm{E}+08$ \\
\hline 3 & Mixed & & & & & \\
\hline
\end{tabular}

Table 5: Limiting concentrations of radionuclides in milk that can be landspread on both dairy and mixed farms when land not used for food production

\begin{tabular}{|c|c|c|c|c|c|c|}
\hline \multirow{2}{*}{$\begin{array}{l}\text { Period of restriction, } \\
\text { months }\end{array}$} & \multirow{2}{*}{ Farm Type } & \multicolumn{5}{|c|}{ Limiting Concentrations $\mathrm{Bg} \mathrm{kg}^{-1}$} \\
\hline & & ${ }^{89} \mathrm{Sr}$ & ${ }^{90} \mathrm{Sr}$ & ${ }^{134} \mathrm{Cs}$ & ${ }^{737} \mathrm{Cs}$ & ${ }^{131} \mathrm{I}$ \\
\hline 1 & Dairy & $3.67 \mathrm{E}+09$ & $1.10 \mathrm{E}+08$ & $5.52 \mathrm{E}+05$ & $1.32 \mathrm{E}+06$ & $5.37 \mathrm{E}+09$ \\
\hline 2 & Dairy & $1.83 \mathrm{E}+09$ & $5.49 E+07$ & $2.76 \mathrm{E}+05$ & $6.62 \mathrm{E}+05$ & $2.68 \mathrm{E}+09$ \\
\hline 3 & Dairy & $1.22 \mathrm{E}+09$ & $3.66 \mathrm{E}+07$ & $1.84 \mathrm{E}+05$ & $4.41 \mathrm{E}+05$ & $1.79 \mathrm{E}+09$ \\
\hline 1 & Mixed & $1.08 \mathrm{E}+10$ & $3.22 \mathrm{E}+08$ & $1.62 \mathrm{E}+06$ & $3.88 \mathrm{E}+06$ & $1.57 \mathrm{E}+10$ \\
\hline 2 & Mixed & $5.38 \mathrm{E}+09$ & $1.61 \mathrm{E}+08$ & $8.08 \mathrm{E}+05$ & $1.94 \mathrm{E}+06$ & $7.86 \mathrm{E}+09$ \\
\hline 3 & Mixcd & $3.58 \mathrm{E}+09$ & $1.07 \mathrm{E}+08$ & $5.39 \mathrm{E}+05$ & $1.29 \mathrm{E}+06$ & $5.24 E+09$ \\
\hline
\end{tabular}


Under certain circumstances, milk could be landspread on land not subsequently used for food production e.g. where crops are grown for industrial use. Doses to the public from ingestion would then no longer be of concern. Table 5 gives limiting concentrations when only doses to farmers from spreading milk are considered. These are more than two orders of magnitude higher than the corresponding CFILs.

\subsubsection{Scenarios for evaluating landspreading as a disposal option for contaminated milk}

Two hypothetical, beyond reference accident scenarios were developed to evaiuate the capacity of landspreading as a disposal option for contaminated milk based solely on radiological considerations. The first scenario was based on a release from one of the Magnox reactors at Hinkley A power station, on the north Somerset coast and the source term included ${ }^{134} \mathrm{Cs},{ }^{137} \mathrm{Cs}$ and ${ }^{131} \mathrm{I}$. The second scenario was based on a release from a degraded core accident for a pressurised water reactor at Sizewell and the source term included ${ }^{89} \mathrm{Sr},{ }^{90} \mathrm{Sr},{ }^{134} \mathrm{Cs},{ }^{137} \mathrm{Cs}$ and ${ }^{131} \mathrm{I}$. For each of the radionuclides of interest in each scenario, deposition levels, peak activity concentrations in milk and ban durations were calculated. The NRPB dynamic model FARMLAND [5] was used to provide information on temporal variations in activity concentrations in milk following deposition. This information was used to estimate the average activity concentration in milk over the relevant period of restriction. The limiting concentrations were used to determine whether landspreading would be a radiologically acceptable option for disposal of the contaminated milk in these scenarios. The average activity concentration of each radionuclide in milk at various distances from the source was compared with the limiting concentrations when spreading over a period of time that equated with the ban duration at that distance. It was found that the limiting concentrations were not exceeded in either scenario and it would therefore be possible to landspread all of the waste milk. An example of the data for the worst case considered is presented in Table 6.

Table 6: Application of limiting concentrations for ${ }^{131} \mathrm{I}$ to Hinkley Scenario

\begin{tabular}{|llllll|}
\hline $\begin{array}{l}\text { Distance } \\
\text { from source } \\
(\mathrm{km})\end{array}$ & $\begin{array}{l}\text { Average } \\
\text { activity conc. } \\
\text { in milk } \\
(\mathrm{Bq} / \mathrm{kg})\end{array}$ & $\begin{array}{l}\text { Ban duration } \\
(\text { days })\end{array}$ & $\begin{array}{l}\text { Limiting } \\
\text { conc. } \\
(\mathrm{Bq} / \mathrm{kg})\end{array}$ & $\begin{array}{l}\text { Limiting } \\
\text { conc. } \\
\text { exceeded }\end{array}$ & $\begin{array}{l}\text { \% that can be } \\
\text { landspread }\end{array}$ \\
\hline 0.5 & $1.48 \mathrm{E}+05$ & 68 & $6.59 \mathrm{E}+08$ & No & 100 \\
1 & $7.86 \mathrm{E}+04$ & 57 & $6.59 \mathrm{E}+08$ & No & 100 \\
5 & $1.09 \mathrm{E}+04$ & 30 & $6.59 \mathrm{E}+08$ & No & 100 \\
10 & $4.39 \mathrm{E}+03$ & 23 & $6.59 \mathrm{E}+08$ & No & 100 \\
30 & $1.15 \mathrm{E}+03$ & 13 & $6.59 \mathrm{E}+08$ & No & 100 \\
60 & $4.81 \mathrm{E}+02$ & 7 & $6.59 \mathrm{E}+08$ & No & 100 \\
\hline
\end{tabular}

\subsection{Acceptability}

Landspreading was considered to be an acceptable disposal option to both the National Farmers Union (NFU) and the Environment Agency (EA). EA emphasised that contaminated milk should not be applied at rates in excess of beneficial levels of nitrogen and that appropriate planning was critical to avoid pollution. The NFU was most concerned that farmers should not be liable to prosecution if pollution did occur. However, EA considered that blanket immunity from enforcement action for any pollution incident might encourage inappropriate disposal of milk.

\section{RECOMMENDATIONS}

- To establish a group of stakeholders to develop a more detailed plan for landspreading milk following a nuclear accident. Given the current uncertainty in existing legislation, as well as different 
perspectives on landspreading milk, the group should include representatives from the Department for the Environment, Food and Rural Affairs, EA and NFU. However, because of the implications of landspreading contaminated milk on the food chain, representation from FSA and NRPB may also be advisable. This group could work in support of the UK Agriculture and Food Countermeasures Working Group (AFCMWG), a diverse group of stakeholders convened to assist in the development of strategies for responding to environmental contamination incidents involving radioactivity. Establishment of a subgroup on landspreading would complement the work of other subgroups of the AFCWG that are taking forward more site specific plans for emergency monitoring at dairies and disposal of milk to sea via long sea outfalls.

- To carry out a detailed environmental assessment of landspreading large quantities of milk.

\section{CONCLUSIONS}

In the event of a nuclear accident, the imposition of Council Food Intervention Levels (CFILs) could lead to the rapid generation of large quantities of milk considered unfit for human consumption. Landspreading is a technically feasible and relatively inexpensive disposal option for milk that appears acceptable in principle to both farmers and regulators. Milk containing radionuclides with activity concentrations of more than a factor of 10 higher than the CFIL can be spread at current application rates without exceeding a dose of $10 \mu \mathrm{Svy}^{-1}$ to members of the public from food subsequently grown on that land. However, the high BOD and nitrogen content of milk may limit the amounts that can be spread in sensitive areas. Limited storage capacity and availability of suitable land are additional factors that can further limit the overall capacity of this option. For two hypothetical beyond reference accident scenarios, all waste milk could be disposed of by landspreading based solely on radiological considerations. Clarification of legislative aspects and the development of more detailed plans are two issues that could usefully be addressed through the setting up of a working group.

\section{Acknowledgements}

The work was originally funded jointly by the Ministry of Agriculture, Fisheries and Food (MAFF), the Environment Agency (EA) and the National Radiological Protection Board (NRPB). The contribution from MAFF became the responsibility of the Food Standards Agency (FSA) with effect from 1 April 2000 .

\section{References}

[1]CEC Off. J. Eur. Commu. L211:1-3 (1989).

[2] J.K. Marchant and A.F. Nisbet, NRPB-R329 (2001).

[3]MAFF: Ministry of Agriculture, Fisheries and Food. Code of good agricultural practice for the protection of water. MAFF Publications, London (1998).

[4]MAFF: Ministry of Agriculture, Fisheries and Food. Code of good agricultural practice for the protection of air. MAFF Publications, London. (1998).

[5] J. Brown and J. R. Simmonds, NRPB-R273, London, TSO (1994)

[6]Chadwick, L. The Farm Management Handbook. SAC, Edinburgh (1999).

[7] MAFF. Pesticide safety directorate's handbook. Appendix 1C. Ministry of Agriculture, Fisheries and Food, London. (1996).

[8] LAEA, LAEA Safety Series No 89 (1998) 